\title{
ON THE ORIGIN OF COMPRESSIONAL INTRAPLATE STRESSES IN SOUTH AMERICA
}

\author{
JORGE A. MENDIGUREN* and FRANK M. RICHTER**
}

\begin{abstract}
Intraplate stresses in middle South America are not negligible. We report thrust faulting mechanisms for five intraplate earthquakes, which indicate a dominant horizontal deviatoric compressional stress oriented in a NW-SE direction. We conclude that this state of stress is due to forces connected with spreading on the mid Atlantic ridge and resistive forces exerted by the Caribbean plate to the north and the Nazca plate to the west. The existence and nature of the resistive forces is inferred from earthquake mechanisms and geological evidence presented in other studies. All the available intraplate stress data for Nazca and South America indicate that both plates are under deviatoric compression generated at spreading centers. The absence of tensional earthquake focal mechanisms, particularly in the Nazca plate near the trench, suggests that the forces associated with the gravitational sinking of subducted lithosphere are locally compensated. We present a simple numerical calculation of a non-subducting plate to show how the compressional deviatoric stresses in middle South America can be used to estimate an upper bound of about $10^{21}$ poise for theviscosity of the mantle.
\end{abstract}

RESUMO: Esforços intra-placas na região central da América do Sul não são negligíveis. Neste trabalho relatamos mecanismos de falhamento tipo thrust, os quais indicam esforço compressional deviatórico dominantemente horizontal, orientado na direção NWSE. Concluímos que esta situação de esforço é devida a forças relacionadas à expansão na cadeia meso-atlântica e as forças de resistência exercidas pela placa Caribeana ao norte e pela placa de Nazca a oeste. A existência e a natureza das forças de resistência são inferidas a partir de mecanismos de terremotos e evidências geológicas relatadas em outros estudos. Todos os dados de esforços intra-placas mostram compressão deviatórica, gerada em centros de expansão. A ausência de mecanismos focais de terremotos tensionais, particularmente na placa de Nazca nas proximidades da trincheira, sugere que as forças associadas com a subsidência gravitacional da litosfera, são compensadas localmente. Ê aqui apresentado um cálculo numérico simples para uma placa que não esteja sofrendo subducção, para mostrar como os esforços deviatóricos compressionais, na região central da América do Sul, podem ser usados para estimar um limite superior de cerca de $10^{21}$ poises para a viscosidade do manto.

INTRODUCTION The importance of intraplate stresses as constraints for models of the driving mechanism of plate tectonics was pointed out by Mendiguren (1971). Horizontal compressional stress in the direction of sea floor spreading was found for a shock in the middle of the Nazca plate. This was interpreted as indicating forces pushing the plate away from the East Pacific Rise and evidencing that the subducting slab under the Andes did not exert a significant pull on the horizontal portion of the Nazca plate.

\footnotetext{
* Departamento de Geociências, Universidade de Brasília - Brasília - Brasil.

** Department of the Geophysical Sciences, University of Chicago - Chicago - Illinois 60637 - U.S.A.
} 
Forces pushing the lithosphere away from the ocean ridge are part of models proposed by Orowan (1964), Hales (1969), Jacoby (1970) and Artyushkov (1973). Nevertheless Isacks and Molnar (1969), Elsasser (1969), McKenzie (1969), Turcotte and Schubert (1971), Richter (1973) have indicated that the gravitational pull of the subducting portion of the lithosphere could be an important driving force for plate motion. Numerical models by Smith and Toksoz (1972) confirmed the importance of those gravitational forces within the sinking portion of the plate, but they and Forsyth and Uyeda (1975) found that the gravitational forces are approximately balanced by local forces opposing the downward motion of the plate.

In a series of papers, Solomon and Sleep (1974), Solomon et al., (1975) and Richardson et al., (1976) studied numerical models of worldwide plate motions and driving force systems, and concluded that data of intraplate stresses constitute important constraints. They also point out that intraplate stresses, summarized in Sykes and Sbar (1973), are sparcely known and a denser coverage is required for further refinement of their driving force models. As there are no intraplate stress data for South America, the aim of this study is to determine intraplate stresses in that region by analysing source mechanisms for all available events with suitable data and to interprete the stress system by a simple driving force model.

SOURCE MECHANISM OF INTRAPLATE EARTHQUAKES IN MIDDLE SOUTH AMERICA As in the case with other plates, large intraplate earthquakes in South America are rare. The scarcity of data is accentuated by the poor coverage of local stations in vast regions, which makes it difficult to determine the source mechanism of moderate size events. Nevertheless, widespread microearthquake activity and the occurrence of some events with magnitude larger than 6 shows that intraplate stresses in South America are not negligible. The 5 nodal plane solutions presented here are the result of an exhaustive search of the data. Table I gives the source parameters of the events.

Table I - Earthquakes Parameters

\begin{tabular}{clccccccc}
\hline $\begin{array}{l}\text { Event } \\
\text { number }\end{array}$ & Date & H & M & S & Lat. & Long. & Depth & $m_{\mathrm{b}}$ \\
\hline \hline 1 & Jan 31 1955 & 05 & 03 & 02.0 & $12.5 \mathrm{~S}$ & $57.4 \mathrm{~W}$ & normal & 6.75 \\
2 & Mar 01 1955 & 01 & 46 & 13.0 & $19.9 \mathrm{~S}$ & $36.7 \mathrm{~W}$ & normal & 6.5 \\
3 & Feb 13 1964 & 11 & 21 & 46.8 & $18.1 \mathrm{~S}$ & $56.8 \mathrm{~W}$ & 33 & 5.3 \\
4 & Oct 24 1972 & 15 & 36 & 32.5 & $21.7 \mathrm{~S}$ & $40.5 \mathrm{~W}$ & 10 & 4.9 \\
5 & Swarm 1975-6 & & & & $20.2 \mathrm{~S}$ & $44.7 \mathrm{~W}$ & 1 & $<3.5$ \\
\hline
\end{tabular}

Event № 1. This magnitude 6.75 event is the largest earthquake which has occurred in modern times in Brazil. The epicenter is located in a sparcely populated area near Serra do Tombador, in Mato Grosso. Fig. 1 shows its nodal plane solution. 
All the critical $P$ wave data constraining the solution were read from original records. The same is true for data of all other events. The $S$ wave polarization angle was determined using Mendiguren's (1968) method. The solution shown in Fig. 1 is the best fit to $P$ and $S$ data. It is not tightly constrained, but any solution compatible with the available $P$ data will have a dominant thrust component. Therefore the stresses in the region are characterized by a dominant horizontal deviatoric compression with a maximum in NW-SE direction. The whole possible azimuth range for the compression axis corresponding to all nodal plane solutions compatible with $P$ data exclusively is also shown in Fig. 1 .

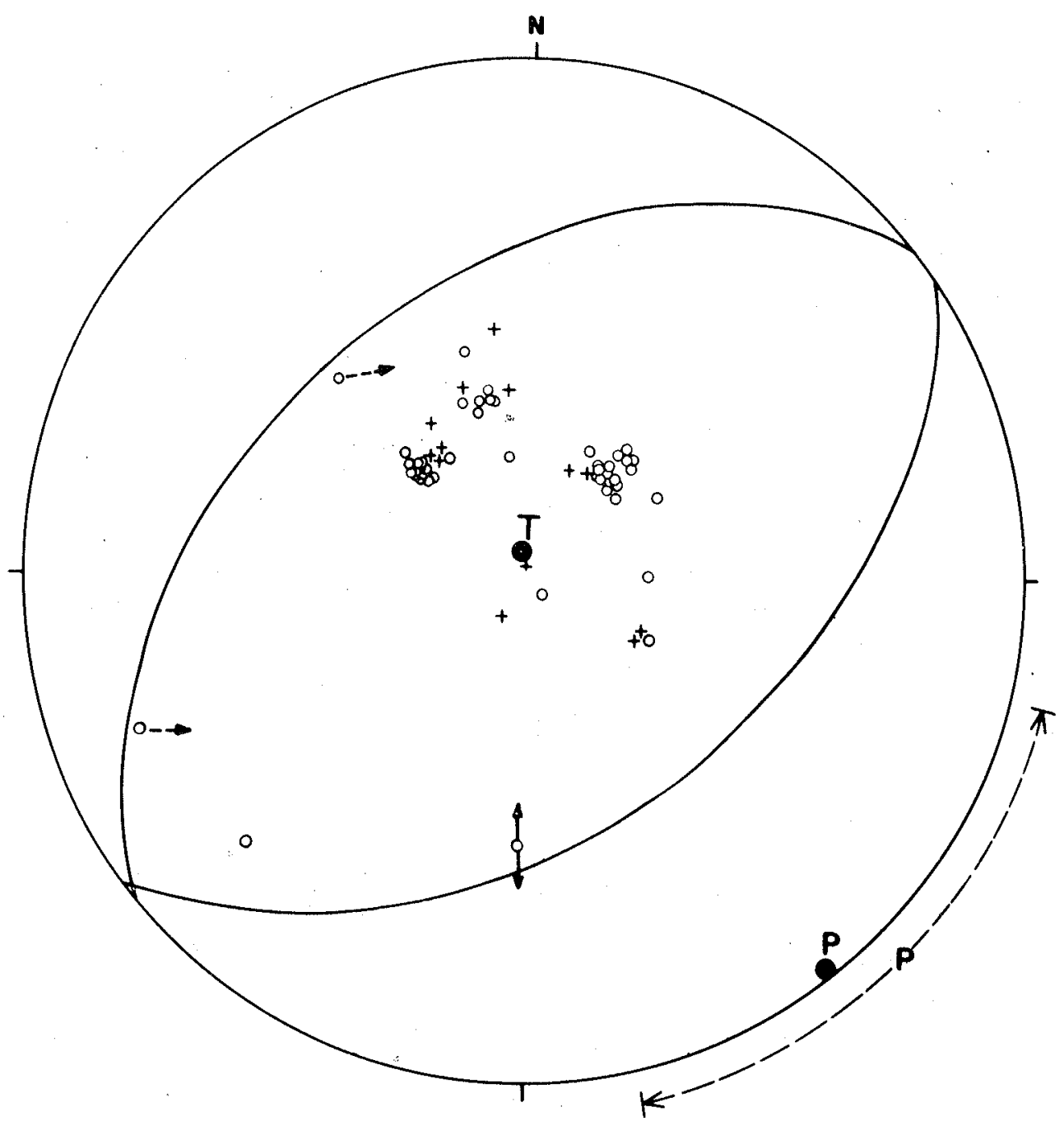

Figure 1 - Nodal plane solution for event number 1. Equal area projection on the lo hemisphere. Open and full circles indicate compression and dilatation first motion respe vely. Arrows indicate $\mathbf{S}$ wave polarization direction. Pressure and tension axis are indic: by symbols $P$ and $T$ respectively. Possible range of pressure axis azimuth compatible wi wave data is shown by dotted line and arrows 
Event No 2. The epicenter of this magnitude 6.4 earthquake is located $300 \mathrm{~km}$ from the shore, slightly north of the Victoria-Trindade ridge. This particular geological setting makes it possible that the source mechanism could reflect stresses of topographic origin (Artyushkov, 1973) related to the Victoria-Trindade ridge, besides the sought long wave intraplate stress system. The first motion of $P$ shown in Fig. 2 is compatible with a predominant thrust motion and a corresponding horizontal compressional deviatoric stress. The data allows for a wide range of nodal plane solutions. Fig. 2 shows the solution which best fit $P$ and $S$ data and the possible azimuth range of the pressure axis direction for all solutions compatible with $P$ data only.

Event No. 3. This shallow event, magnitude 5.3, occurred near the Bolivia-Brazil border within a $300 \mathrm{~km}$ wide sedimentary basin. Fig. 3 shows our prefered nodal plane solution and the whole range of possible compressional axis azimuths compatible with $P$ data. Again a thrust fault type mechanism predominates over the strike

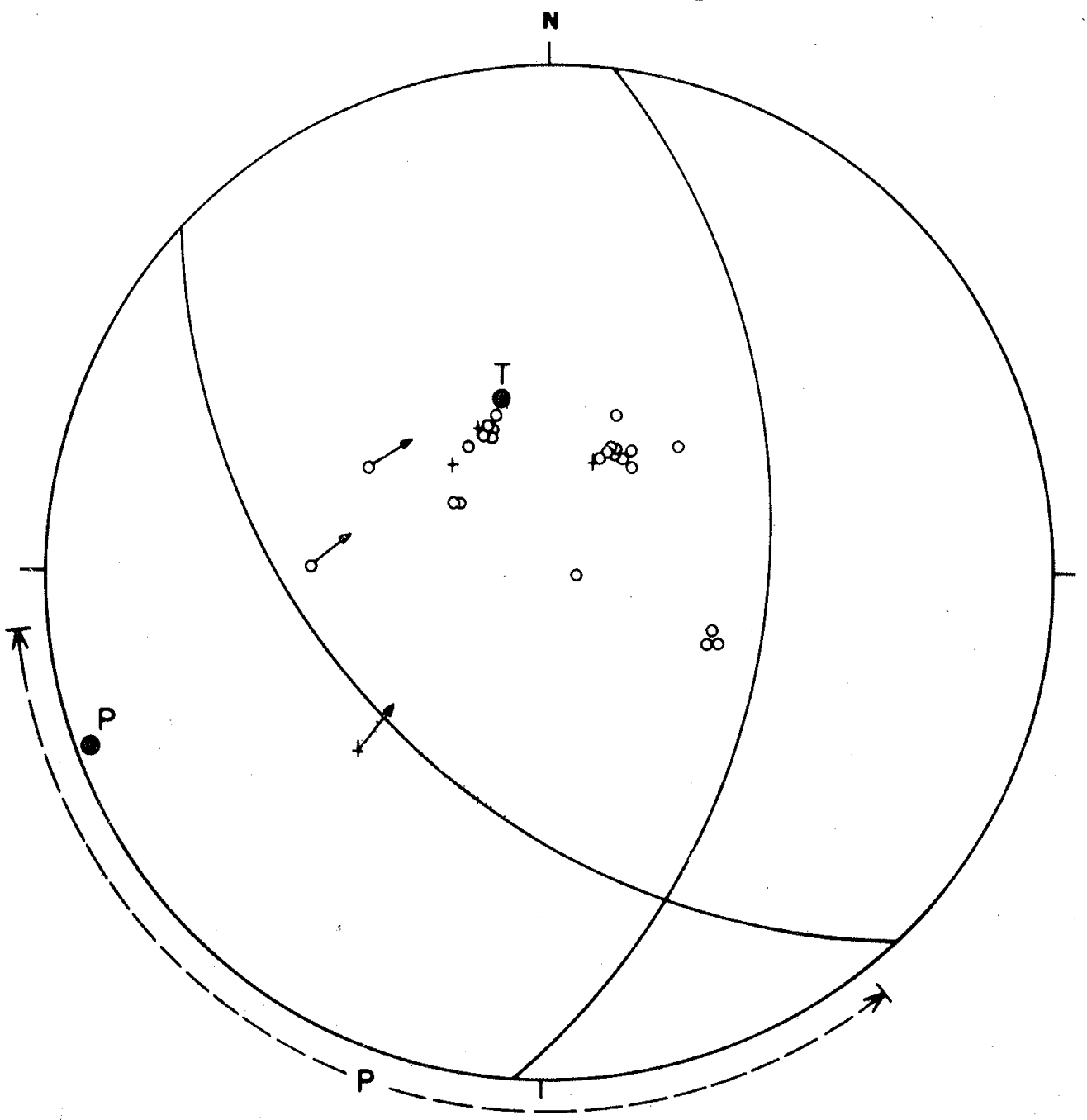

Figure 2 - Nodal plane solution for event number 2. See captions in figure 1 


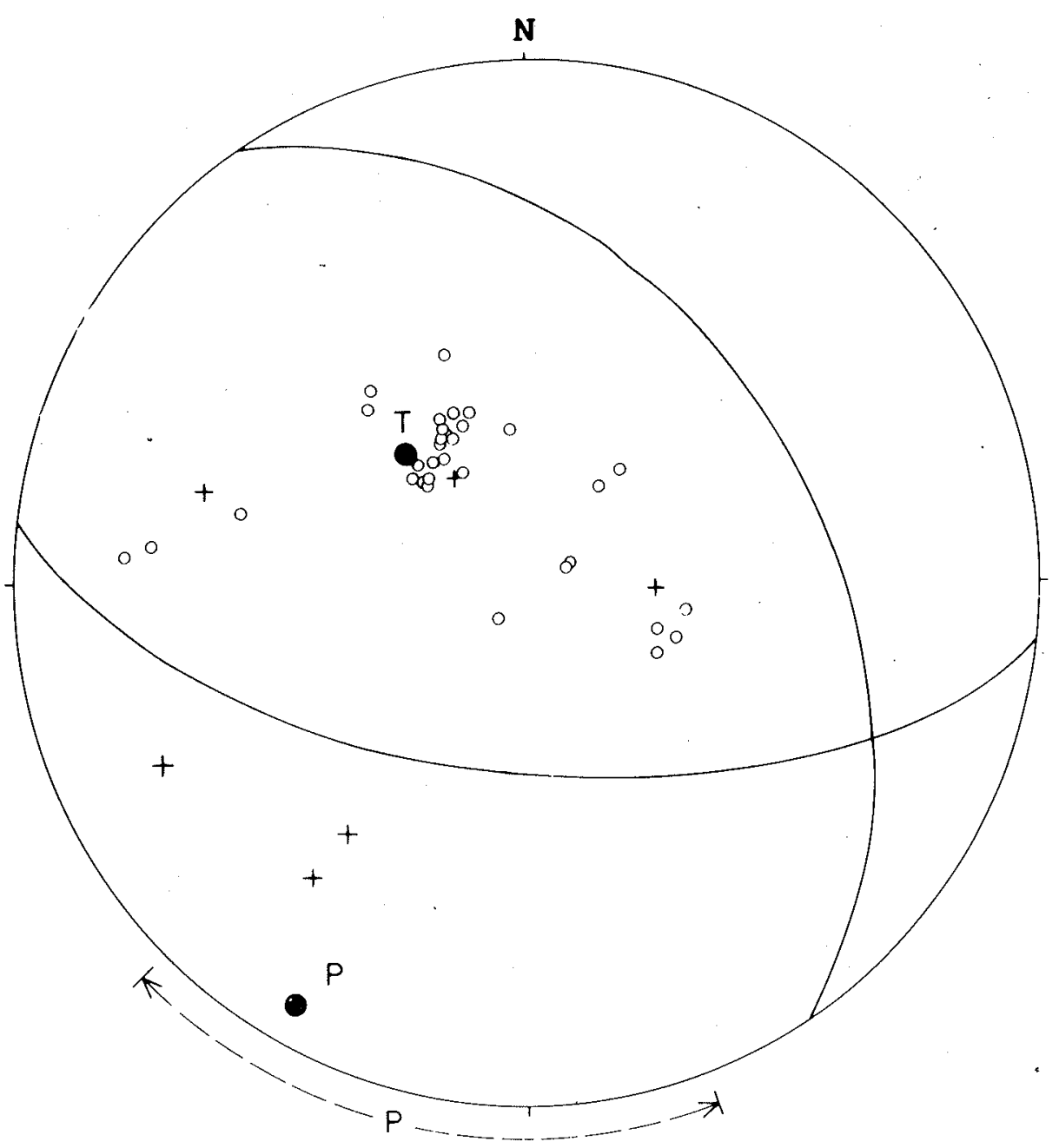

Figure 3 - Nodal plane solution for event number 3. See captions in figure 1

slip component, indicating a dominant horizontal deviatoric compressional stress in the region.

Event N. 4. This event occurred in the Atlantic continental shelf, within the Campos basin, $55 \mathrm{~km}$ from the shore. The few available $P$ compressional first motion data allows a wide range of nodal plane solutions, but again it suggest a predominant thrust motion and a horizontal deviatoric compression in the region. Station BDF received a weak $P$ dilatation while PNS, a high gain station, recorded very weak $P$ and $S$ waves, a pattern which is expected for rays emerging close to the null 
axis. $P$ wave alone allows for almost any azimuth of the compression axis. If data of LPS are interpreted as indicating the location of the null axis the corresponding nodal plane solution is that shown in Fig. 4.

Event N. 5. This is a composite solution of hundreds of small events, magnitude less than 3.5 and depth around $1.0 \mathrm{~km}$, which occurred in a region of precambrian gneiss and moderate relief. The data correspond to observations made over one and half years and no change in source mechanism was noted in that period. Again a well defined NW-SE horizontal compressional axis associated with thrust faulting is indicated by the data.

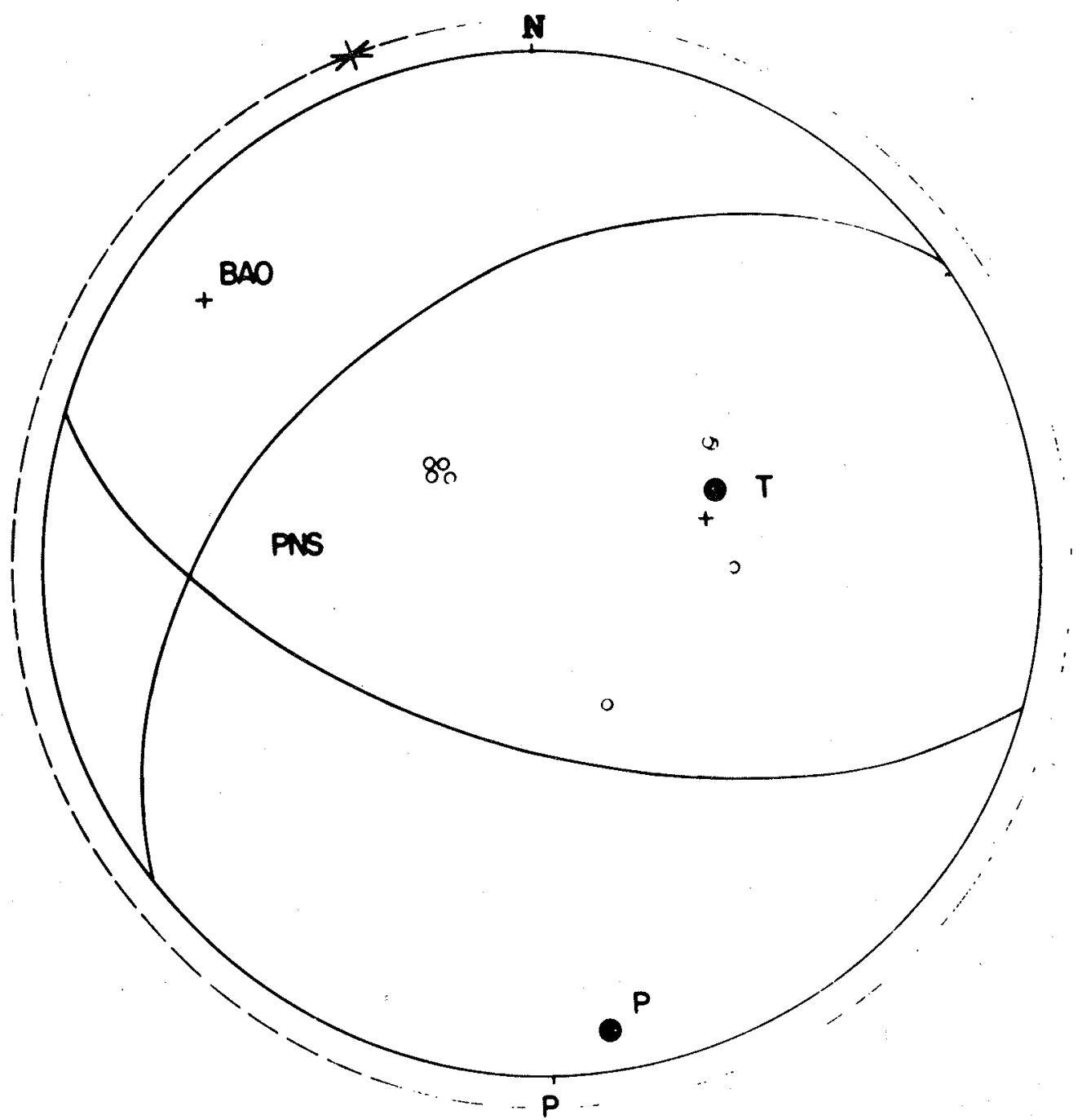

Figure $4-$ Nodal plane solution for event number 4 . See captions in figure 1 
INTRAPLATE STRESSES IN SOUTH AMERICA Only events number 1 and 5 present well defined nodal plane solutions, while the others, specially $N$ ․ 4 , allow for a wide range of azimuth for the compressional axis. Nevertheless all of them share the same characteristics of being reverse faults type events. This indicates that the dominant deviatoric intraplate stress is a horizontal compression. The location of the epicenter and the possible azimuth range for the compressional stress in each case is shown in Fig. 5. A common azimuth for the compressional deviatoric axis, compatible with all the source mechanisms is approximately NW-SE. Event No 2 shows the largest deviation from the average azimuth. Based on this data we concluded that middle South America is under dominant horizontal compressional deviatoric stress with a maximum approximately in NW-SE direction.

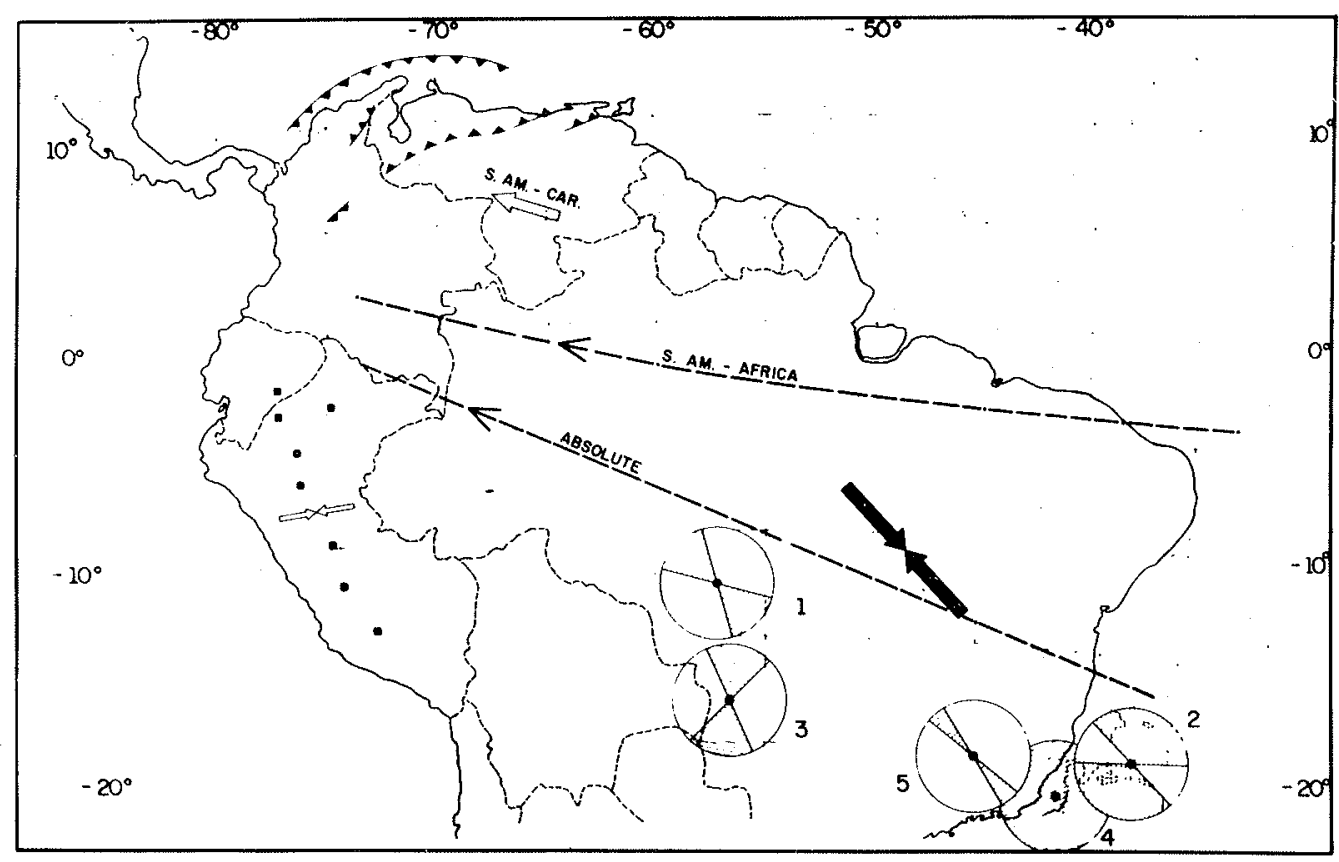

Figure 5 - Location of events under study. The azimuth range for pressure axis of nodal plane solution is shown by full sectors. Large full arrows indicate the inferred deviatoric compressional stress direction in South America. Dashed arrow at the top indicates the direction of relative motion between Caribbean and South American plates. Thrust faulting shown at the top was sketched from Jordan (1975). Small full squares to the left and a small open arrow indicate epicenter of shallow events and the pressure axis direction of their nodal plane solution after Stauder (1975). The direction of absolute plate motion of South America and sea floor spreading direction were drawn after Minster et al. (1974)

OCEANIC SPREADING CENTERS AS THE MAIN SOURCE OF LITHOSPHERE' STRESS The observed intraplate compressional stresses in South America may be explained by the following force system: Forces at the spreading cente? (Middle Atlantic ridge) push the South American plate on its eastern boundary; the 
corresponding plate motion away from the ridge is resisted by drag on its base and neighbour plates on the north and west boundaries, namely along the Pacific subduction zone and along the South America-Caribbean plate boundary. This is supported by geological evidence and source mechanism of earthquakes in the plate boundary region. Jordan (1975) has shown from geological evidence and relative plate motion that the Caribbean-South American plate boundary is a transform fault combined with a thrust of South America over the Caribbean plate, see Fig. 5. The thrust fault component implies a resistance of the Caribbean plate to the northward component of relative motion of South America, which is consistent with the observed intraplate compressional stresses.

On the boundary between South America and Nazca plate, Stauder (1975) found that shallow shocks as far as $400 \mathrm{~km}$ to the east of the Pacific trench are thrust type mechanism events with a dominant EW horizontal compressional axis (see Fig. 5). Those events are probably too close to the subduction zone to represent pure intraplate stress, but their consistent EW compressional axis may be interpreted as a net resistence of the Nazca plate to the westward motion of South America by forces transmitted across the plate boundary.

Horizontal deviatoric compressional stresses are observed to the west of the $\mathrm{Pa}$ cific subduction zone in the middle of the Nazca plate (Mendiguren, 1971), and also to the east within the South American plate, as shown in this study. From this simple picture we may conclude that the whole lithosphere between the East Pacific Rise and the middle Atlantic ridge is subjected to a dominant deviatoric compressional stress generated by forces on the oceanic spreading centers. This also implies that the tensional stresses generated by the gravitational pulling of the sinking slab under the Andes are compensated by local forces, as pointed out by Forsyth and Uyeda (1975) and Richter (1977), and its tensional effect on the Nazca plate is of secondary importance respect of compressive stresses generated by pushing forces at the East Pacific Rise (Mendiguren, 1971).

On the continental side of the Pacific subduction zone we should consider the effect of the induced convection current behind the sinking lithosphere, McKenzie (1969), Sleep and Toksoz (1971) and Richter (1973, 1977). We may argue that in the case of an oceanic-continental plate collision the secondary convection cells are of local importance. Also, in some regions the Nazca plate sinks under South America following a very shallow dip angle, Barazangi and Isacks (1976), which enhances the stresses and may help explain Stauder's observations of compressional events as far as $400 \mathrm{~km}$ from the trench.

In next section it will be shown how compressional intraplate stresses can be used to set an upper bound value to mantle viscosity under South America by using a numerical model of a non-subducting plate.

AN UPPER BOUND TO MANTLE VISCOSITY UNDER SOUTH AMERICA If we assume that the observed compressional state of deviatoric stress in South America results from forces maintaining the plates' motion, then a simple model of a non-subducting plate can be used to illustrate how the observations place an upper bound on the viscosity of the upper mantle.

Consider a two-dimensional representation of a thin plate moving away from a ridge crest and towards a subduction zone where it is itself not subducted. Assuming 
that body forces are negligible except in the vicinity of the ridge crest and given that inertial terms are insignificant, the deviatoric stress within the lithosphere satisfies the equation

$$
\frac{\partial p_{\mathrm{ij}}}{\partial x_{\mathrm{j}}}=0
$$

where $p_{\mathrm{ij}}$ is the force in the $x_{\mathrm{i}}$ direction acting on a surface with normal in the $x_{\mathrm{j}} \mathrm{di}$ rection. In two dimensions $(x, z)$ the balance of forces in the $x$-direction requires

$$
\frac{\partial p_{x x}}{\partial x}+\frac{\partial p_{x z}}{\partial z}=0
$$

Integrating this expression. vertically across the thickness $\ell$ of the plate and dividing by the plate thickness, we have

$$
\frac{\partial \bar{p}_{x x}}{\partial x}=-\frac{1}{\ell} p_{x z \ell \ell}
$$

where $\bar{p}_{\mathrm{xx}}=\frac{1}{\ell} \int_{0}^{\ell} \mathrm{p}_{\mathrm{xx}} \mathrm{dz}$, which we shall call the mean horizontal stress in the lithosphere; and $p_{\mathrm{xz}(\ell)}$ is the shear stress or drag on the base of the plate. Equation (3) can be integrated for $\bar{p}_{\mathrm{xx}(\mathrm{x})}$ given the shear stress on the base of the plate and a value of $\bar{p}_{\mathrm{xx}}$ at some $x$. We will use as the required boundary condition a stress of 200 bars at the ridge crest, which arises from the action of body forces acting on the elevated sea floor. The value of the stress used is typical of the estimates which have been made of "ridge pushing" by various authors (for further discussion see Richter 1977). Integrating (3) away from the ridge crest we find

$$
\bar{p}_{x \times(x)}=-200-\frac{1}{\ell} \int_{0}^{x} p_{x z(\ell)} d x
$$

where the stress is measured in bars. The earthquake mechanisms given in this paper require that $\bar{p}_{\mathrm{x} x}<0$ (compression) for essentially all $x$. Keeping in mind that $p_{\mathrm{x} z}$ is itself negative when representing a resistance to the plates' motion, the requirement that $\bar{p}_{\mathrm{xx}}<0$ will require that $p_{\mathrm{xx}}$ be on average small. This statement can be made more specific by considering a particular model of a moving, non-subducting plate from which shear stress on the base of the plate can be determined.

Fig. 6 shows a simple two-dimensional model of a plate moving over a uniform viscosity upper mantle and bounded by a ridge at one end and a subduction zone at the other. The subducting plate to the left moves ten times faster than the non-subducting plate in which we are interested. The solution for motion in a Newtonial 

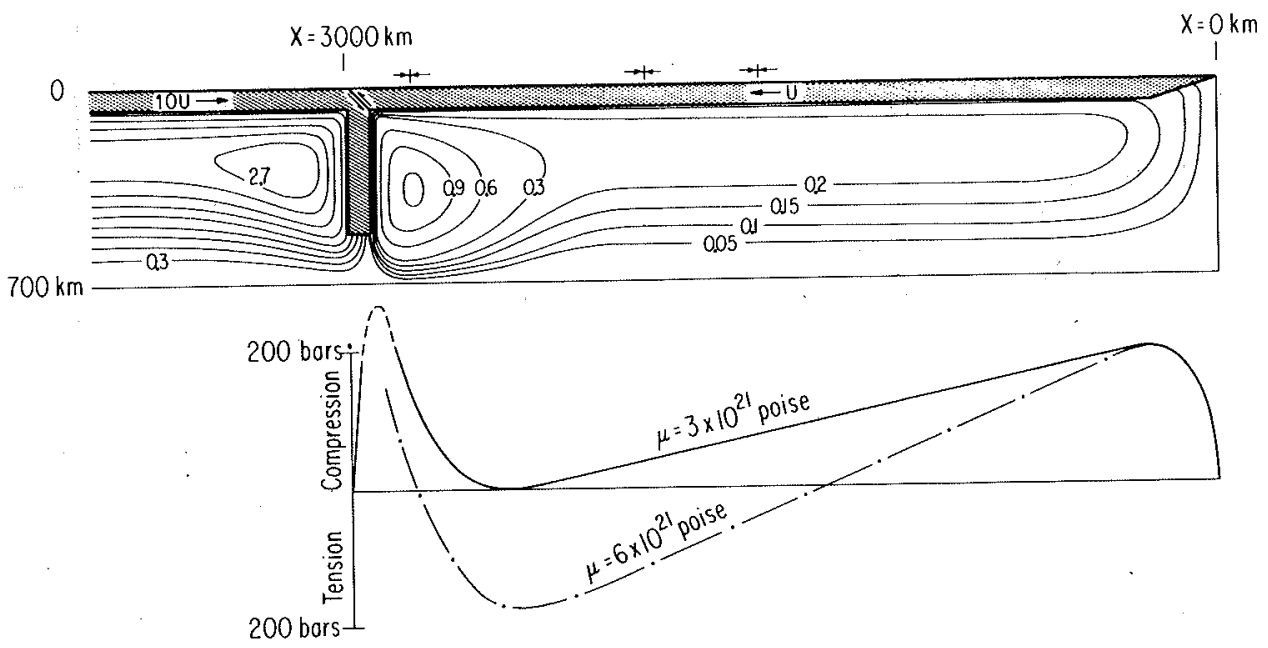

Figure 6 - The upper part of the figure shows the streamlines of a uniform viscosity Newtonian fluid below moving lithosphere plates. The subducting plate on the left moves ten times faster than the one on the right. Note the change in contour interval (in units of velocity $U$ times depth) for streamlines in the right hand side of the figure. A plot of the mean horizontal deviatoric stress in the lithosphere $\left(\bar{p}_{\mathrm{xx}}\right.$ as defined in text) is also shown for two values of the viscosity of the upper mantle. Three hypothetical compressional focal mechanisms are used to show how such information places a bound on the viscosity of the models' upper mantle. For a velocity $U$ of $1 \mathrm{~cm} \mathrm{yr} \mathrm{yr}^{-1}$ and the dimensions given in the figure, the viscosity of the upper mantle cannot be much greater than $3 \times 10^{21}$ poise if it is to explain the compressional focal mechanisms

fluid consistent with these moving plates is shown by the streamlines, obtained by methods described in detail in Richter (1977). In that paper an attempt is made to justify the usefulness of such simple models as representations of plate tectonics for purposes of discussing the balance of forces responsible for plate motions. The flow seen in Figure 6 is used to evaluate the integral in equation (4) and the averaged stress function $\bar{p}_{\text {xx }}$ for two choices of upper mantle viscosity are shown in the same figure. The dashed portion of the $\mu=3 \times 10^{21}$ poise curve has been sketched, reflecting the uncertainty in the magnitude of forces acting on the trust fault between plates and that the shear stress on the base of the non-subducting lithosphere is unrealistically modelled in the immediate vicinity of the corner. The model shear stresses in the corner region become large like the inverse of distance from the corner, which is unrealistic for an actual physical system. In the earth it is likely that local melting due to shear stress heating will keep the stresses finite. Finite, but how large? We don't know, but this source of uncertainty affects only the maximum value of compression achieved in the dashed region of the curve but does not affect the shape or even the magnitude of the curve elsewhere.

As an example of how intraplate stresses serve to bound the viscosity of the up. per mantle, three hypothetical compressional focal mechanisms are included in the figure. For a plate of the dimensions shown, only viscosities less than about $3 \times 10^{21}$ poise are acceptable as larger values of the viscosity would result in widespread ten- 
sion in the plates' interior. The event nearest the trench is the result of a local balance between the forces acting on the thrust fault bounding the plates and the stress on the base of the plate arising from the circulation induced by the rapidly moving downgoing slab. The model uses a vertical downgoing slab, but more realistic subduction angles will have only a local effect and do not affect arguments regarding bounds on upper mantle viscosity.

The same arguments used in connection with Fig. 6 can be used to estimate a bound on the viscosity below the South American plate. If the depth extent of the mass flux associated with plate tectonics is $700 \mathrm{~km}$, the viscosity (assumed uniform) below the South American plate must be less than about $10^{21}$ poise. If we allow for the possibility that the continental portion of plates are subject to more drag than oceanic portions, the stress diagram would show a change in slope at the continental margin. The viscosity bound would be increased by about a factor of two and would apply to the viscosity of "continental" upper mantle. It should be added that a sufficiently low drag on the base of the South American plate could result from a low viscosity zone at the base of the plate and therefore the bound on viscosity does not rule out viscosities greater than $10^{21}$ poise at greater depth. The compressive events described by Stauder (1975) are sufficiently near the trench that they are most likely the result of local compression such as that shown in Figure 6.

The most compelling conclusion is the general one that the state of stress within the South American plate implies that the drag on its base must be sufficiently small so that when integrated over the entire plate it not exceed the "ridge pushing". For a particular representation of the mass flow associated with the moving South American plate, the statement of small drag can be converted into a bound on the viscosity of the upper mantle $\left(<10^{21}\right.$ poise $)$. Given that the model used is two-dimensional, it cannot be used to explain the northwesterly trend of the intraplate compressive axis compared to the more E-W trend found by Stauder (1975) for events nearer the trench. That these trends are different is not surprising. We have interpreted the events near the trench to result from a local process and thus the principal compression should be in the direction of the relative velocity vector along that boundary. The truly intraplate stresses on the other hand should depend on the absolute velocity of the plate and the three-dimensional distribution of boundaries. Solomon et.al. (1975) have begun modelling the intraplate stresses arising from plate tectonic processes on a spherical model, but their results generally show the tensional axis where we find compression. Since the stresses they determine are not easy to relate intuitively to the distribution of boundaries and absolute velocity of a plate, it is not possible to account for the discrepancy between their model and our observations.

CONCLUSIONS Widespread microearthquake activity and the occasional occurrence of magnitude 6 earthquakes shows that intraplate stresses in South America are not negligible. Nodal plane solutions for 5 intraplate earthquakes with epicenter in different geological settings, ranging from oceanic basin to mid continent show a consistent thrust faulting mechanism with an average maximum compression in NW-SE direction.

Sykes and Sban (1973) concluded that world data of intraplate stresses do not show a consistent pattern that could clearly indicate the origin of those stresses. That is probably due to the geometrical complexity of some plate boundaries and their corresponding plate interaction, and also the complexity added by reactivation 
of old zones of weakness. For the South American-Nazca plate system the boundaries are relatively simple and the present data, even scarce, can only lead to the conclusion that the dominant compressional stresses in the lithosphere are due to pushing forces at oceanic spreading centers.

Forces on the middle Atlantic ridge push the South American plate to the west causing the observed compressional stress pattern. The motion of South America away from the middle Atlantic ridge is resisted by the Caribbean plate to the north and the Nazca plate to the west. The resistence of the Caribbean plate is indicated by modern thrust faulting and relative interplate motion, as shown by Jordan (1975). EW thrust faulting of shallow events to the east of the Nazca-South America subduction zone, as determined by Stauder (1975), are interpreted as evidencing that compressional stresses are transmitted from Nazca to South America plate across the subduction zone. Within this model, compressional stresses observed in the Nazca plate are due to East Pacific Rise spreading forces pushing the plate to the east while gravitational pulling by the subducting lithosphere under the Andes should be of secondary importance in determining the state of stresses in the oceanic portion of the plate (Mendiguren, 1971). This is consistent with the Smith and Toksoz (1972), Forsyth and Uyeda (1975), and Richter (1977) conclusions that the buoyancy forces on the downgoing slab are locally compensated. We interprete the dominant compressional stresses observed in South America as due to pushing forces on the middle Atlantic ridge, while mantle drag forces due to secondary convection behind the sinking lithosphere are of only local importance, and thus they do not alter the compressional pattern caused by pushing forces acting on the middle Atlantic ridge. The observations of intraplate stresses can be used within the framework of a simplified numerical model for a non-subducting plate, as proposed by Richter (1977), to determine an upper bound for the mantle viscosity under South America. We conclude that the viscosity in the asthenosphere under South America should be smaller than $10^{21}$ poise.

Acknowledgements We are grateful to colleagues from many seismological observatories who answered our request and patiently dug out from their files the original of old seismograms. This study was partially supported by grants from Conselho Nacional de Desenvolvimento Científico e Tecnológico do Brasil and the United States National Science Foundation under grant NSF-EAR 75-17170.

\section{REFERENCES}

ARTYUSHKOV, E.V., 1973. Stresses in the lithosphere caused by crustal thickness inhomogeneities. J. Geophys. Res., 78: 7675-7708.

BARAZANGI, M., and ISACKS, B.L., 1976. Spatial distribution of earthquakes and subduction of the Nazca plate beneath South America. Geology, 4: 686-692.

ELSASSER, W.M., 1969. Convection and stress propagation in the upper mantle. The application of modern physics to the earth and planetary interiors. 223-246, ed. 'S.K. Runkorn, Wiley-Interscience, New York.

FORSYTH, D., and UYEDA, S., 1975. On the relative importance of the driving forces of plate motion. Geophys. J.R. Astr. Soc., 43: 163-200. 
HALES, A.L., 1969. Gravitational sliding and continental drift. Earth Planet. Sci. Lett., 6: 31-34

ISACKS, B. and MOLNAR, P., 1969. Mantle earthquake mechanism and sinking of the litosphere. Nature, 223: 1121-1124.

JACOBY, W.B., 1970. Instability in the upper mantle and global plate movements. J. Geophys. Res., 75: 5671-5680.

JORDAN, T.H., 1975. The present-day motion of the Caribbean plate. J. Geophys. Res., 80: $4433-4439$.

MCKENZIE, D.P., 1969. Speculations on the consequences and causes of plate motion. Geophys. J. R. Astr. Soc., 18: 1-13.

MENDIGUREN, J.A., 1971. Focal mechanism of a shock in the middle of Nazca plate. J. Geophys. Res., 76: 3861-3879.

MENDIGUREN, J.A., 1968. Study of focal mechanism of deep earthquakes in Argentina using non linear particle motion of S waves. Bull. Seism. Soc. Am., 59:1449-1473.

OROWAN, E., 1964. Continental drift and the origin of mountains. Science, 146: 10031010.

RICHARDSON, R.M., SOLOMON, S.C. and SLEEP, N.H., 1976. Intraplate stress as an indicator of plate tectonic driving forces. J. Geophys. Res., 81: 1847-1856.

RICHTER, F.M., 1973. Dynamical models for sea floor spreading. Rev. Geophys. Space Phys., 2: 223-287.

RICHTER, F.M., 1977. On the driving mechanism of plate tectonics. Tectonophysics, 38: $66-81$.

SLEEP, N.H. and TOKSOZ, M.N., 1971. Evolution of marginal basins. Nature, 233: 548550.

SOLOMON, S.C. and SLEEP, N.H., 1974. Some simple physical models for absolute plate motion. J. Geophys. Res., 79: 2557-2567.

SOLOMON, S.C., SLEEP, N.H. and RICHARDSON, R.M., 1975. On the forces driving plate tectonics: Inferences from absolute plate velocities and intraplate stress. Geophys. J.R. Astr. Soc., 42: 769-801.

SMITH, A.T. and TOKSOZ, M.N., 1972. Stress distribution beneath island arcs. Geophys. J. R. Astr. Soc., 29: 289-318.

STAUDER, W., 1975. Subduction of the Nazca plate under Peru as evidenced by focal mechanisms and by seismicity. J. Geophys. Res., 80: 1053-1064.

SYKES, L.R. and SBAR, M.L., 1973. Intraplate earthquakes, lithosphere stresses and the driving mechanism of plate tectonics. Nature, 245: 298-302.

TURCOTTE, D.L. and SCHUBERT, G., 1971. Structure of the olivine-spinel phase boundary in the descending lithosphere. J. Geophys. Res., 76: 7980-7987. 